\title{
ANALISIS KUALITAS PELAYANAN PADA RESTORAN XYZ DALAM RANGKA MENGUKUR KEPUASAN PELANGGAN
}

\author{
Stella \\ Program Studi Magister Manajemen Universitas Tarumanagara \\ atshstella@gmail.com \\ Eko Harry Susanto \\ Program Studi Magister Manajemen Universitas Tarumanagara
}

Masuk : 14-11-2017, revisi : 07-12-2017 diterima untuk diterbitkan : 07-12-2017

\begin{abstract}
The good quality of the service is one of important aspect for any restaurants, especially for various old restaurants in Jakarta to stay in the completion in this industry. In this research, the researcher used XYZ Restaurant as the object of this research to give feedback to XYZ Restaurant to know whether their service quality has already met their customers' expectation, so that XYZ Restaurant can keep competing in this global competition. XYZ Restaurant is Chinese Food restaurant that can be said has been long enough in this industry, We live in the era where food and restaurant business is continuously expanding in Indonesia, whether in a similar business or not, from traditional as well modern. Writer used service quality for the method in this research and dimensions that measured are tangibility, reliability, responsiveness, assurance and empathy, in which compares perception or what customer's feels compared with what customer expect from the dimensions. From the calculations performed by the writer, overall, XYZ Restaurant score of service quality is negative it means perception score is lower than expectation score. Therefore, XYZ Restaurant need to fix dimension of Tangibility and Assurance, because is lower than customer's expectation. Meanwhile for reliability dimension, Responsiveness dimension and Empathy dimension have to be in keep because its already higher than customer expectation. Overall, XYZ Restaurant need to fix their service quality because their service is haven't meet customer's expectation.
\end{abstract}

Keywords: Service Quality, Restaurant, Customer Satisfaction

\section{PENDAHULUAN}

\section{Latar Belakang}

Di zaman yang semakin modern ini, semakin banyak restoran cepat saji dari luar negeri ataupun dari dalam negeri dibandingkan dengan restoran-restoran keluarga. Peluang ini yang banyak dimanfaatkan oleh para pebisnis untuk membuka restoran keluarga yang banyak dicari saat berulang tahun ataupun hari raya. Karena peluang ini, maka terjadilah persaingan yang kuat dan cepat, yang menyebabkan banyak bisnis jasa dan retail mencari keuntungan dengan cara membedakan bisnisnya dengan pesaingnya. Untuk bisnis jasa, salah satunya adalah dengan meningkatkan kualitas penyampaian jasanya. Tidak seperti barang yang dapat dinilai langsung seperti ketahanan dan kecacatannya, jasa merupakan sesuatu yang abstrak dan sulit dinilai.

Secara umum, tingkat kepuasan konsumen atau kepuasan pelanggan adalah tingkat perasaan konsumen setelah membandingkan harapannya dengan apa yang telah diterima dari produk atau jasa itu sendiri. Biasanya jika harapannya sesuai dengan apa yang ia dapatkan maka konsumen tersebut akan terus menggunakan jasa dari perusahaan tertentu. Dalam penelitian ini, peneliti menggunakan Restoran XYZ sebagai objek penelitiannya untuk memberikan masukan kepada Restoran XYZ apakah kualitas pelayanannya sudah sesuai dengan ekspektasi pelanggan, agar Restoran XYZ dapat terus bertahan di persaingan global ini. 
Restoran XYZ adalah restoran Chinese Food yang dapat dikatakan sudah cukup lama bergerak dalam bidang ini, namun karena perkembangan zaman semakin banyak restoran yang masuk ke Indonesia, baik dalam usaha yang sejenis maupun tidak sejenis, dari yang tradisional maupun modern. Dikutip dari Qraved.com bahwa sepanjang tahun 2013, tercatat kunjungan orang Indonesia ke restoran mencapai 380 juta kali dan menghabiskan total USD 1,5 miliar. Semaraknya kebiasaan makan di restoran ini juga ditopang dengan pertumbuhan restoran kelas menengah dan atas hingga 250 persen dalam lima tahun terakhir. Selain itu data Badan Pusat Statistik juga mencatat sepanjang tahun 2012 hingga akhir 2014, pertumbuhan jumlah perusahaan industri mikro sektor makanan mengalami peningkatan signifikan. Pada tahun 2012 tercatat, sebanyak 2.812 .747 perusahaan makanan skala mikro. Namun angka ini melonjak tajam pada tahun 2013, sebanyak 74.268 perusahaan mikro, menjadi 2.887.015 perusahaan makanan skala mikro. Kemudian, angka itu melonjak sekitar $450 \%$ dari tahun 2013 atau sebanyak 333.548 perusahaan makanan skala mikro pada akhir 2014, menjadi sebanyak 3.220.563 perusahaan makanan skala mikro di seluruh Indonesia.

Sedangkan, berdasarkan pada data BPS dari tahun 2007-2011, pertumbuhan usaha restoran di Jakarta semakin meningkat. Dari awalnya 720, 1.028, 1.311, 1.359 dan pada tahun 2011 sebesar 1.361 restoran. Di Indonesia hanya di Jakarta saja yang peningkatannya begitu signifikan hingga ratusan, di kota-kota lain hanya berkisar puluhan restoran. Hal ini merupakan peluang atau ancaman yang besar bagi restoran XYZ untuk terus mempertahankan bisnisnya.

\section{Pokok Masalah}

Masalah yang akan diteliti dalam penelitian ini adalah sebagai berikut:

1. Bagaimana harapan pelanggan terhadap kualitas pelayanan di restoran XYZ?

2. Bagaimana persepsi pelanggan terhadap kualitas pelayanan di restoran XYZ?

3. Sejauh mana kesenjangan antara kualitas pelayanan yang diharapkan dengan pelayanan yang di rasakan pelanggan (persepsi)?

\section{Tujuan Penelitian}

1. Untuk mengetahui harapan pelanggan atas kualitas pelayanan di restoran XYZ.

2. Untuk mengetahui persepsi pelanggan atas kualitas pelayanan di restoran XYZ.

3. Untuk mengetahui sejauh mana kesenjangan antara kualitas pelayanan yang diharapkan dengan pelayanan yang dirasakan pelanggan (persepsi).

\section{Ruang Lingkup Penelitian}

Penelitian hanya pada konsumen yang sedang makan di restoran XYZ.

\section{Manfaat Penelitian}

Bagi perusahaan: Diharapkan restoran mendapatkan masukan sehingga dapat memperbaiki kualitas pelayanannya dan hasil akhirnya adalah untuk tercapainya kepuasan pelanggan, dan mencegah konsumen beralih ke restoran lain.

Bagi pihak lain: Diharapkan penelitian ini dapat bermanfaat bagi pihak lain yang mau meneliti mengenai kualitas pelayanan.

\section{TELAAH KEPUSTAKAAN}

Jasa

Jasa cukup sulit dibedakan secara khusus dengan barang. Hal ini disebabkan pembelian suatu barang kerap kali disertai dengan jasa-jasa tertentu, begitu pula sebaliknya. Jasa menurut Zeithaml \& Bitner (2003:101), service is all economic activities whose output is not physical product or construction in generally consumed at that time it is product, and provides added value in forms. Zeithaml \& Bitner mengartikan bahwa jasa adalah kegiatan ekonomi yang hasil akhirnya bukan berupa produk fisik atau suatu produk yang langsung di konsumsi saat itu dan ditambahkan nilai pada saat itu. Dari definisi jasa tersebut, dapat dilihat bahwa jasa adalah sesuatu yang tidak berwujud dan dapat ditawarkan ke konsumen untuk memenuhi kebutuhan dan keinginannya. 


\section{Kualitas Jasa}

Kualitas jasa bepusat pada upaya pemenuhan kebutuhan dan keinginan pelanggan serta ketepatan penyampaiannya untuk mengimbangi harapan pelanggan. Pengertian kualitas jasa menurut Tjiptono (2011:59) adalah tingkat keunggulan yang diharapkan dan pengendalian atas tingkat keunggulan tersebut untuk memenuhi keinginan pelanggan.

Dengan kata lain ada dua faktor utama yang mempengaruhi kualitas jasa yaitu expected service dan perceived service. Apabila jasa yang diterima atau dirasakan (perceived service) sesuai dengan yang diharapkan, maka kualitas pelayanan jasa dipersepsikan baik dan memuaskan. Jika jasa yang diterima melampaui harapan pelanggan, maka kualitas jasa yang dipersepsikan sebagai kualitas yang ideal. Sebaliknya, jika jasa diterima lebih rendah daripada yang diharapkan maka kualitas jasa dipersepsikan buruk. Dengan demikian baik tidaknya kualitas pelayanan jasa tergantung pada kemampuan penyedia jasa dalam memenuhi harapan pelanggannya secara konsisten.

\section{Dimensi kualitas jasa}

Dalam perkembangannya Zeithaml dkk (1990:26) menyimpulkan bahwa kesepuluh dimensi diatas dapat di rangkum menjadi 5 (lima) dimensi pokok (Zeithaml, Parasuraman, Berry, 1990:262-264), yaitu:

1. Reliability (keandalan): Menurut Kotler (2003:455), reliability adalah kemampuan memenuhi jasa yang dijanjikan secara terpercaya dan akurat. Pelanggan ingin melakukan hubungan bisnis dengan perusahaan yang dapat memberikan pelayanan dengan cepat, tepat dan dapat diandalkan terutama dari atribut jasa yang ditawarkan.

2. Responsiveness (daya tanggap): Menurut Kotler (2003:455), responiveness adalah kesediaan untuk membantu pelanggan dan memberikan layanan dengan cepat. Perusahaan harus dapat melihat proses penyampaian jasa dan bagaimana mengatasi permintaan-permintaan melebihi sudut pandang pelanggan.

3. Assurance (jaminan): Menurut Kotler (2003:454), assurance adalah pengetahuan, kompetensi, kesopanan, sifat dapat dipercaya dari staf. Bebas dari bahaya, resiko, keraguraguan. Dimensi ini mencangkup dimensi competence, courtesy, credibility, dan security.

4. Emphaty (empati): Menurut Kotler (2003:454), empathy adalah adanya rasa peduli dan perhatian kepada setiap pelanggan secara individual dengan maksud mengoptimalkan jasa. Dimensi ini mencangkup dimensi access, communication, dan understanding the customer. Karena perlu disadari bahwa masing-masing pelanggan adalah unik dan perlu diperlakukan secara spesial.

5. Tangibles (berwujud): Menurut Kotler (2003:455), tangibles adalah penampilan fasilitas fisik, peralatan, karyawan, dan bahan komunikasi. Tangibles sering digunakan perusahaan jasa untuk meningkatkan image perusahaan karena menyiratkan kualitas dari jasa yang ditawarkan.

\section{Kepuasan Pelanggan}

Menurut Kotler dalam Lupiyoadi (2014:228) "Kepuasan merupakan tingkat perasaan dimana seseorang menyatakan hasil perbandingan atas kinerja produk jasa yang diterima dengan yang diharapkan." Menurut Kotler dan Amstrong (2004) dalam Jasfar (2012:19) menyatakan bahwa kepuasan pelanggan adalah perasaan senang atau kecewa yang muncul setelah membandingkan persepsi pelanggan terhadap hasil dari suatu porduk dengan harapannya.

\section{Konsep Servqual}

Konsep service quality yang telah disusun oleh Parasuraman, Zeithaml, dan Berry, merupakan konsep yang banyak dipakai dalam pengukuran kualitas pelayanan. Ketiga tokoh tersebut telah mengidentifikasi lima gap atau kesenjangan dalam proses produksi jasa (Husein Umar, 2003:54-57): 
GAP 1

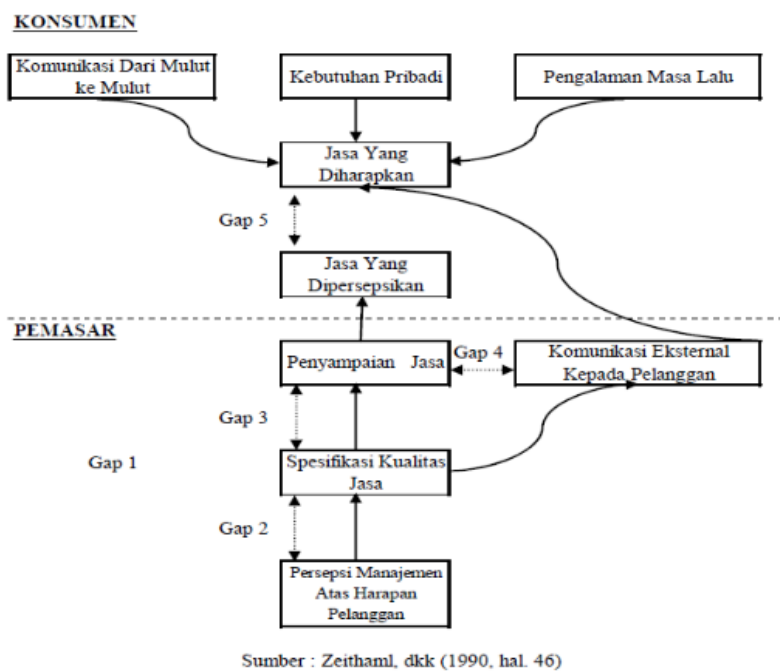

Gambar 1

Konsep Service Quality

Kesenjangan yang muncul antara harapan konsumen dengan persepsi manajemen. Kesenjangan ini muncul sebagai akibat dari ketidaktahuan manajemen tentang kualitas jasa apa yang diharapkan konsumen. Akibatnya, desain dan standar jasa yang disampaikan menjadi tidak layak, sehingga perusahaan tidak dapat memenuhi janjinya kepada konsumen. Jadi, kesenjangan harapan konsumen dengan persepsi manajemen merupakan sumber munculnya kesenjangan (gap) lainnya.

GAP 2

Kesenjangan antara persepsi manajemen tentang harapan konsumen dan spesifikasi kualitas jasa. Manajemen disini meliputi semua pihak yang bertanggung jawab dan mempunyai otoritas untuk menciptakan atau atau mengubah kebijaksanaan, prosedur dan standar jasa. Kesenjangan ini muncul karena para manajer menetapkan spesifikasi kualitas jasa berdasarkan pada apa yang mereka percayai sebagai yang diinginkan konsumen, padahal belum tentu akurat. Akibatnya, banyak organisasi jasa telah memfouskan kepada kualitas teknis, sementara pada kenyataannya hal yang di anggap lebih penting oleh konsumen adalah kualitas yang berkaitan dengan penyajian jasa. Munculnya gap ini adalah karena tidak adanya interaksi langsung antara manajemen dengan konsumen, keenganan untuk menanyakan harapan konsumen, dan ketidaksiapan manajemen dalam mengkomunikasikan keduanya.

GAP 3

Kesenjangan antara spesifikasi kualitas jasa dan jasa yang disajikan. Kesenjangan ini biasanya muncul pada jasa yang sistem penyampaiannya sangat bergantung kepada karyawan. Persepsi yang akurat tentang harapan konsumen memang penting, tetapi belum cukup untuk menjamin penyampaian kualitas jasa yang terbaik. Para manajer mengalami kesulitan dalam menerjemahkan pemahaman mereka terhadap harapan konsumen ke dalam spesifikasi kualitas jasa. Oleh karena itu, syarat lain yang perlu dipenuhi adalah diciptakannya desain standar yang mencerminkan persepsi yang akurat tentang harapan konsumen. Gap ini mengindikasikan perlunya desain dan standar jasa yang berorientasi kepada konsumen yang dibangun berdasarkan keperluan konsumen yang mudah dipahami oleh konsumen dan diukur oleh konsumen. Standar operasi tersebut ditetapkan sesuai dengan harapan dan prioritas konsumen, bukan berdasarkan sudut efisiensi dan efektivitas perusahaan.

GAP 4

Kesenjangan antara penyajian jasa aktual dan komunikasi eksternal kepada konsumen. Janji yang disampaikan mungkin secara potensial bukan hanya meningkatkan harapan yang akan dijadikan sebagai standar kualitas jasa yang akan diterima konsumen, akan tetapi juga akan meningkatkan persepsi tentang jasa yang akan disampaikan kepada mereka. 
GAP 5

Kesenjangan antara jasa yang diharapkan dan jasa aktual yang diterima konsumen. Kesenjangan ini menunjukan perbedaan antara kerja aktual yang diterima konsumen dan kerja yang diharapkan.

\section{Potensi Penyebab Kurangnya Kualitas Pelayanan}

SERVQUAL memfokuskan diri pada pengukuran dan pemahaman atas persepsi pelanggan mengenai kualitas pelayanan. Melalui penelitian yang dilakukan oleh Zeitaml, diketahui bahwa terdapat 4 kesenjangan sebagai penyebab terjadinya kegagalan kualitas pelayanan yang diterima pelanggan dan kegagalan berikutnya terdapat pada kesenjangan 5 .

Kunci untuk menutup kesenjangan 5 adalah dengan cara menutup kesenjangan 1 sampai 4. Kesenjangan 5 adalah kesenjangan antara pelayanan yang diterima dengan pelayanan yang diharapkan. Kesenjangan ini terjadi apabila pelanggan mengukur kinerja/prestasi perusahaan dengan cara/ukuran yang berbeda atau keliru mempersepsikan kualitas pelayanan tersebut. Kunci penyebab atas kualitas yang diharapkan pelanggan adalah komunikasi dari mulut ke mulut, kebutuhan pribadi, pengalaman masa lalu, dan komunikasi eksternal dari perusahaan. Dapat dilihat pada gambar berikut:

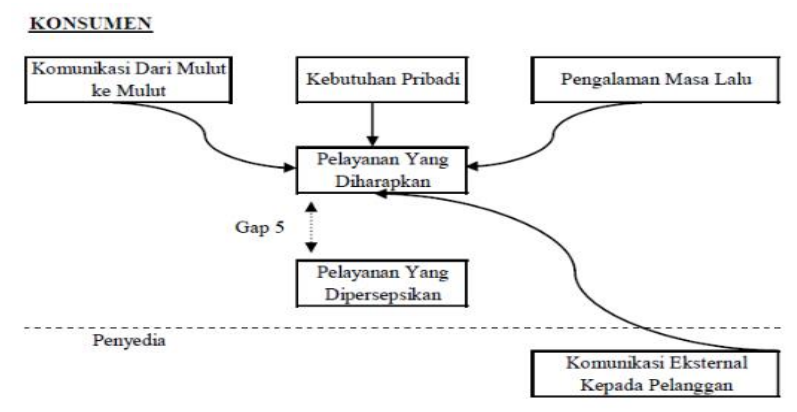

Gambar 2

Gap 5 pada Konsep Service Quality

\section{METODOLOGI PENELITIAN}

\section{Jenis \& Periode Penelitian}

Jenis penelitian ini adalah penelitian deskriptif (deskriptif research), yang bertujuan untuk menguraikan tentang sifat-sifat (karakteristik) suatu keadaan serta menginterpretasikan hubungan fenomena yang diselidiki. Dalam penulisan ini mengenai kualitas pelayanan hubungannya dengan kepuasan pelanggan. Periode penelitian dimulai dari Januari 2017 sampai November 2017.

\section{Sumber dan Pengumpulan data}

Sumber data dari penelitian ini adalah konsumen XYZ yang telah selesai bersantap di restoran dengan usia 17-60 tahun, yang dilakukan setiap hari Sabtu dan Minggu hingga jumlah data yang dibutuhkan terkumpul. Kemudian penulis menanyakan kesediaan konsumen untuk mengisi kuesioner yang telah disusun. Populasi pada penelitian ini adalah semua konsumen yang datang ke restoran XYZ. Sampel pada penelitian ini adalah konsumen yang datang ke Restoran XYZ dan mau mengisi kuisioner penelitian ini.

\section{Metode Penarikan Sampel}

Pengambilan sampel dalam penelitian ini menggunakan metode Purposive Sampling. purposive sampling menurut Sugiyono (2010:218) yaitu : "purposive sampling adalah teknik pengambilan sampel sumber data dengan pertimbangan tertentu". Malhotra (1993) memberikan panduan ukuran sampel yang diambil dapat ditentukan dengan cara mengalikan jumlah variabel dengan 5, atau 5x jumlah variabel. Dengan demikian jika jumlah variabel yang diamati berjumlah 20, maka sampel minimalnya adalah 5 × $20=100$.

\section{Variabel Penelitan dan Operasionalisasi Variabel}

Kualitas Pelayanan akan diukur berdasarkan 5 variabel kualitas pelayanan (Zeithaml, Parasuraman \& Berry, 1990:263-264), yaitu: 
Variabel Tangibles

1. Restoran yang baik memiliki area parkir yang luas dan gedung yang menarik. (T1)

2. Restoran yang baik memiliki ruangan yang menarik. (T2)

3. Restoran yang baik memiliki karyawan yang bersih, rapi dan berpakaian pantas. (T3)

4. Restoran yang baik memiliki dekorasi yang mencerminkan citra dan harganya. (T4)

5. Restoran yang baik memiliki daftar menu yang mudah dibaca dan menarik dilihat. (T5)

6. Restoran yang baik memiliki peralatan makan/minum yang baik dan mencerminkan citra restorannya. (T6)

7. Restoran yang baik memiliki ruang restoran yang nyaman dan lapang. (T7)

8. Restoran yang baik memiliki toilet yang bersih. (T8)

9. Restoran yang baik memiliki ruang restoran yang bersih. (T9)

10. Restoran yang baik memiliki kursi yang nyaman diduduki. (T10)

Variabel Reliability

11. Restoran yang baik melayani pelanggan sesuai dengan waktu yang dijanjikan. (RL1)

12. Jika terjadi suatu kesalahan restoran yang baik dengan cepat memperbaikinya. (RL2)

13. Restoran yang baik adalah restoran yang dapat diandalkan dan konsisten. (RL3)

14. Restoran yang baik memberikan bon pembayaran dengan tepat. (RL4)

15. Restoran yang baik menghidangkan makanan/minuman sesuai dengan yang saya pesan. (RL5)

Variabel Responsiveness

16. Ketika ramai pengunjung, restoran yang baik tetap melayani dengan cepat dan baik. (RS1)

17. Restoran yang baik memberikan layanan yang ramah dan cepat. (RS2)

18. Restoran yang baik selalu berusaha keras melayani permintaan khusus saya. (RS3)

Variabel Assurance

19. Restoran yang baik memiliki karyawan-karyawan yang dapat menjawab pertanyaan pelanggan dengan lengkap. (A1)

20. Restoran yang baik membuat saya merasa nyaman dan percaya diri ketika saya datang ke restorannya. (A2)

21. Restoran yang baik memiliki karyawan yang dapat dan bersedia memberikan informasi mengenai menu dan komposisinya. (A3)

22. Restoran yang baik menghidangkan makanan/minuman yang aman (bebas bahan berbahaya/bahan terlarang). (A4)

23. Restoran yang baik memiliki karyawan yang terlihat sudah di latih dengan baik, memiliki kemampuan dan pengalaman. (A5)

24. Restoran yang baik mendukung karyawannya sehingga mereka dapat bekerja dengan baik. (A6)

Variabel Empathy

25. Restoran yang baik memiliki karyawan yang tahu apa yang diinginkan dan dibutuhkan pelanggannya. (E1)

26. Restoran yang baik membuat saya merasa special. (E2)

27. Restoran yang baik mengantisipasi kebutuhan dan keinginan khusus saya. (E3)

28. Restoran yang baik memiliki karyawan yang simpatik dan meyakinkan jika terjadi suatu kesalahan. (E4)

29. Restoran yang baik memperhatikan kepentingan tamu dengan tulus. (E5)

Yang akan diukur adalah tingkat kualitas pelayanan yang diperoleh dengan menghitung selisih antara pelayanan yang dirasakan (persepsi) dengan pelayanan yang diharapkan. Pengukuran dari masing-masing variabel diperoleh dari hasil pengisian kuisioner yang didapat dari pengumpulan data primer. Untuk penilaian pertanyaan menggunakan skala Likert, dengan angka 1 (sangat tidak setuju) sampai 7 (sangat setuju).

Skor SERVQUAL = Skor Persepsi - Skor Harapan 
Cara perhitungan $\Sigma(\mathrm{Nj} * \mathrm{Ni})=($ jumlah jawaban STS $* 1)+($ jumlah jawaban ATS $* 2)$ $+($ jumlah jawaban TS $* 3)+($ jumlah jawaban $\mathrm{N} * 4)+($ jumlah jawaban AS $* 5)+($ jumlah jawaban $\mathrm{S} * 6)+($ jumlah jawaban $\mathrm{SS} * 7)$.

Hasilnya sebagai berikut:

Skor Positif (+)

Hal ini berarti persepsi pelanggan lebih besar dari harapan pelanggan, yang berarti kualitas pelayanan Restoran XYZ memiliki kualitas pelayanan yang baik.

Skor Negatif (-)

Hal ini berarti persepsi pelanggan lebih kecil dari harapan pelanggan, yang berarti kualitas pelayanan Restoran XYZ memiliki kualitas pelayanan yang kurang baik.

\section{ANALISIS DAN BAHASAN TEMUAN Uji Validitas}

Hasil Korelasi untuk 30 responden dan tiap-tiap butir pertanyaan baik untuk harapan maupun persepsi menunjukan hasil yang signifikan. Hal ini dapat dilihat oleh nilai $r$ hitung $>r$ tabel. Dimana $\mathrm{r}$ tabel pada tingkat kepercayaan 95\% dan $\mathrm{N}=30$ responden adalah 0.3061 , sehingga kuisioner ini dapat dinyatakan valid untuk penelitian ini.

\section{Uji Reliabilitas}

Output SPSS memberikan nilai alpha cronbach untuk keseluruhan skala pengukuran sebesar 0.978. Nilai Alpha cronbach ini jelas berada di atas batas minimal 0.70 sehingga dapat disimpulkan bahwa kuisioner ini realibel untuk mengukur kualitas pelayanan Restoran XYZ.

\section{Hasil Penelitian}

\begin{tabular}{|l|r|r|r|}
\hline Dimensi & Persepsi & Harapan & Skor Servqual \\
\hline Tangibility & 5.81 & 5.87 & -0.06 \\
\hline Reliability & 6.06 & 6.01 & 0.05 \\
\hline Responsiveness & 5.89 & 5.87 & 0.02 \\
\hline Assurance & 5.96 & 6.09 & -0.13 \\
\hline Empathy & 5.94 & 5.83 & 0.11 \\
\hline Rata-rata & $\mathbf{5 . 9 3}$ & $\mathbf{5 . 9 4}$ & $\mathbf{- 0 . 0 1}$ \\
\hline
\end{tabular}

\section{Skor TANGIBILITY secara keseluruhan}

Skor SERVQUAL $=5,81-5,87=-0,06$

Secara keseluruhan hal ini mengidikasikan bahwa tangibility dari Restoran XYZ terdapat beberapa yang belum dapat memenuhi harapan konsumen, hal ini mungkin karena desainnya yang masih tradisional. Selain itu, karena yang datang adalah konsumen dengan usia produktif yang sangat aktif di sosial media, restoran XYZ jika di foto tidak terlihat mewah dan modern yang bisa diunggah ke social media. Selain itu yang dikeluhkan lagi adalah permasalahan ruang parkir yang hanya sedikit, ada juga karyawan yang berpakaian kurang rapih. Selain itu juga penggunaan piring plastik mungkin membuat beberapa pelanggan merasa tidak nyaman.

\section{Skor RELIABILITY secara keseluruhan}

$$
\text { Skor SERVQUAL = 6,06 - 6,01 = 0,05 }
$$

Hal ini mengidikasikan bahwa reliability dari Restoran XYZ sudah dapat memenuhi harapan konsumen karena pelayanannya yang bisa diandalkan dan memenuhi harapan konsumen.

\section{Skor RESPONSIVENESS secara keseluruhan}

$$
\text { Skor SERVQUAL = 5,89 - 5,87 = 0,02 }
$$

Hal ini mengidikasikan bahwa responsiveness dari Restoran XYZ sudah dapat memenuhi harapan konsumen karena pelayanannya yang cepat dan dapat memenuhi berbagai permintaan konsumennya, artinya Restoran XYZ sangat bertanggung jawab untuk melayani pelanggannya.

\section{Skor ASSURANCE secara keseluruhan}

$$
\text { Skor SERVQUAL = 5,96 - 6,09 = -0,13 }
$$

Hal ini mengidikasikan bahwa assurance dari Restoran XYZ belum dapat memenuhi harapan konsumen karena persepsi konsumen terhadap karyawan yang dianggap belum 
profesional, ada karyawan yang mungkin saat ditanya tidak dapat menjawab dengan lengkap sesuai dengan keinginan pelanggan, karena terkenal dengan restoran chinese food mungkin banyak yang berpikir restoran menjual makanan tidak halal, jadi ada beberapa yang ragu mengenai hal ini, tetapi jika sudah masuk ke restoran ada tulisan "no pork, no lard".

\section{Skor EMPATHY secara keseluruhan}

Skor SERVQUAL = 5,94 - 5,83=0,11

Hal ini mengidikasikan bahwa empathy dari Restoran XYZ sudah dapat memenuhi harapan konsumen karena persepsi konsumen terhadap karyawan yang dianggap peduli dengan kepentingan konsumennya, dengan jumlah karyawan yang sangat mencukupi, restoran juga dapat dengan cepat melayani konsumen jika ada kebutuhan tambahan yang diperlukan.

Skor SERVQUAL Restoran XYZ secara keseluruhan belum dapat memenuhi harapan konsumen, karena skor presepsi masih di bawah skor harapan $(<0)$

\section{KESIMPULAN}

Berdasarkan hasil analisis SERVQUAL dari 5 variabel yang diteliti, Restoran XYZ harus memperbaiki dimensi Tangibility dengan skor SERVQUAL -0,06 dan Assurance dengan skor SERVQUAL -0,13, karena masih dibawah harapan konsumen. Sedangkan untuk dimensi Reliability dengan skor SERVQUAL 0,05, Responsiveness dengan skor SERVQUAL 0,02 dan Empathy dengan skor SERVQUAL 0,11, harus di pertahankan karena sudah melebihi harapan konsumen.

Secara keseluruhan, kualitas pelayanan Restoran XYZ memiliki skor -0.01 sehingga harus memperbaiki pelayanannya karena masih belum dapat memenuhi harapan konsumen agar tercapainya kepuasan pelanggan, dan mencegah konsumen beralih ke restoran lain.

\section{SARAN}

Saran untuk peningkatan kualitas pelayanan Restoran XYZ adalah memperluas parkir kapasitas restoran lebih besar daripada lapangan parkir yang dimiliki, mungkin restoran bisa menyewa lahan parkir di sekitar lokasi dan menyediakan valet agar konsumen tidak perlu berjalan jauh.

Untuk suasana di dalam restoran, mungkin dapat diputarkan lagu-lagu jaman dahulu untuk menyesuaikan dengan usia konsumen yang datang ke restoran. Untuk televisi sebaiknya tidak ada, karena suaranya hanya menggangu dan bertabrakan dengan lagu yang diputar, terkadang yang di putar di televisi adalah acara berita, sehingga dapat menggangu selera makan jika sedang di putar berita kecelakaan atau bencana.

Untuk menambah konsumen yang datang, dapat juga dilakukan kerjasama dengan berbagai bank, agar konsumen yang datang dapat menggunakan bank yang mereka miliki dengan promo-promo dari restoran.

Untuk menjaga konsumen yang sudah berkali-kali datang ke restoran, konsistensi rasa perlu dipertahankan, mungkin bisa diadakan loyalty card atau di berikan voucher.

Seragam dari pelayanannya perlu di perhatikan, apabila sudah terlihat agak kurang layak, mungkin dapat diganti dengan yang baru agar restoran juga terkesan baru.

Untuk memperlihatkan bahwa restoran menyediakan makanan halal, tulisan "NO PORK NO LARD” dapat diletakkan atau di tempel di depan restaurant, mungkin dapat juga dibuatkan spanduknya. Selain itu, dapat juga ditambahkan ruang untuk shalat.

Karyawan juga perlu diberikan pelatihan bagaimana melayani konsumen, menjawab pertanyaan konsumen, agar komsumen dapat mengerti dan mau memesan menu tersebut, dapat diajarkan juga bagaimana menawarkan menu-menu baru agar konsumen mau mencoba menu baru walaupun sudah berkali-kali datang ke restoran XYZ. 
DAFTAR PUSTAKA

Kotler P., \& Armstrong, G. (2012). Principles of Marketing (14 ${ }^{\text {th }}$ ed.). New Jersey: Pearson Prentice Hall

Kotler, P. (2003). Marketing Management (11 ${ }^{\text {st }}$ ed.). New York: Prentice Hall, Inc.

Kotler, P., \& Keller, K. L. (2012). Marketing Management (14 ${ }^{\text {th }}$ ed., Global Edition). New Jersey: Pearson Prentice Hall

Malhotra, N. K. (1993). Marketing Research An Applied Orientation (2 ${ }^{\text {nd }}$ ed.). New Jersey: Prentice Hall International Inc.

Parasuraman, A., Zeithaml, V. A., \& Berry, L. L. (1985). A conceptual model of service quality and its implications for future research. Journal of Marketing, 49(Fall 1985), 41-50.

Sugiyono. (2010). Statistika untuk Penelitian. Bandung: Alfabeta.

Tjiptono, F. \& Chandra. (2011). Service, Quality and Satisfaction (3 ${ }^{\text {rd }}$ ed.). Yogyakarta: Andi. Tjiptono, F. (2011). Pemasaran Jasa. Malang: Bayumedia

Zeithaml, V. A., \& Bitner, M. J. (2013). Service Marketing (1 ${ }^{\text {st }}$ ed.). USA: McGraw Hill Co, Inc.

http://www.tribunnews.com/bisnis/2014/04/02/dalam-5-tahun-jumlah-restoran-kelasmenengah-tumbuh-250-persen?page $=2$ diakses 4 september 2016 pukul 12:10

http://www.mri-research-ind.com/berita-235-surga-kuliner-industri-makanan-ri-melonjaktinggi.html diakses 4 september 2016 pukul 12:17

http://repository.widyatama.ac.id/xmlui/bitstream/handle/123456789/3144/Bab\%202.pdf?seq uence $=7$ diakses 19 sept pukul 18.30

http://www.eurekapendidikan.com/2015/09/defenisi-sampling-dan-teknik-sampling.html

Disalin dan Dipublikasikan melalui Eureka Pendidikan diakses 24/10/2016 pada 10.57

http://www.eurekapendidikan.com/2015/09/defenisi-sampling-dan-teknik-sampling.html

Disalin dan Dipublikasikan melalui Eureka Pendidikan diakses 24/10/2016 pada 10.57 